\title{
Hypothetical Learning Trajectory for Assimilating the Articulated Concepts of Quadratic Function and Equation Through Variational Ideas and the Use of GeoGebra in Pre-University Students
}

\author{
Armando Morales Carballo ${ }^{1 *}(\mathbb{D})$, Angie Damián Mojica ${ }^{1}$ (D), José Efrén Marmolejo Vega ${ }^{1}$ (D)
}

${ }^{1}$ Universidad Autónoma de Guerrero, Guerrero, MEXICO
${ }^{\star}$ Corresponding Author: armandomorales@uagro.mx

Citation: Morales Carballo, A., Damián Mojica, A., \& Marmolejo Vega, J. E. (2022). Hypothetical Learning Trajectory for Assimilating the Articulated Concepts of Quadratic Function and Equation Through Variational Ideas and the Use of GeoGebra in Pre-University Students. International Electronic Journal of Mathematics Education, 17(2), em0678. https://doi.org/10.29333/iejme/11714

\section{ARTICLE INFO}

Received: 20 Jul. 2021

Accepted: 28 Jan. 2022

\begin{abstract}
A theoretical-didactic proposal based on variational ideas and the use of GeoGebra is described as a response to a local problem on the understanding of the concept of function and quadratic equation in pre-university students. The theoretical elements of this work are based on the understanding of concepts and the theory of semiotic registers and representations, while the methodological references were based on hypothetical learning trajectories and the use of dynamic software, considered as a heuristic resource.

The proposal was validated by means of expert criteria. This elaboration contributes with a proposal that breaks with the classical schemes of presentation and treatment of the content, which favors through the incorporation of variational ideas generated with the dynamic software GeoGebra the understanding of the articulated concepts of function and quadratic equation in pre-university students.
\end{abstract}

Keywords: hypothetical learning path, quadratic function, understanding, variation

\section{INTRODUCTION}

The quadratic equation is a mathematical object that is studied starting at the secondary and high school level and continues its study at the higher level in mathematics and related careers, at least in Mexico. Its importance lies in the fact that it is a guiding axis for the development of a considerable part of mathematics and for its application in the resolution of problems within and outside mathematics, in areas such as physics, among others.

\section{Research in the Field of Mathematics Education About Quadratic Functions and Equations}

Research in this field (Arias-Rueda et al., 2020; Cetina et al., 2016; Genicio et al., 2005; Gustin \& Avirama, 2014; Haruna, 2015; Hau-Yon \& Zapata, 2019; Manrique et al., 2017; Mosquera \& Uzuriaga, 2018; Natsai et al., 2020; Ortiz et al., 2020; Vega, 2016; Zakaria et al., 2010) agrees on the importance of the study of the concepts of function and quadratic equation; given the different problems that have been detected in the processes of their teaching and learning from the basic (secondary level, at this level students between 12 and 15 years old are located), pre-university and university levels.

These investigations coincide from their findings that, from the secondary level, students present difficulties in the development of some operations with the concept of a quadratic function (Haruna, 2015; Zakaria et al., 2010), within these operations are those that refer to the definition, the determination of the roots, their representation, and their exemplification in modeling and problem-solving. In pre-university, reference research shows that students present difficulties in the definition of the concept, determination of roots, graphing and their interpretation, for the use of methods of solving the quadratic equation and the application of function and quadratic equation to problem-solving.

In this direction, Manrique et al. (2017) conducted research considering the approaches: methodological, according to schooling, focused on teaching, on learning, and from the applications of the concept in general, this with the purpose of analyzing the trends of research around the quadratic function and equation. After this realization, they concluded that it is necessary to continue in the line of searching for improvements in the teaching and learning processes of this concept. Since in the research they reported that a considerable number of investigations have been projected at the pre-university level and are of quantitative type, in smaller percentage stand out those of qualitative type and even below these approaches, investigations on the concept with mixed approach begin to be identified. From a particular point of view, it is considered that the approaches that have been considered have not had an effective impact on the attention to this problem; therefore, it is considered that qualitative and mixed 
Table 1. Concentrate of information on the responses to the questionnaire

\begin{tabular}{|c|c|c|c|}
\hline Actividad activity & Correct answer & Incorrect answer & No answer \\
\hline 1 & 3 & 26 & 5 \\
\hline 2 & 6 & 24 & 4 \\
\hline 3 & 16 & 10 & 9 \\
\hline 4 & 8 & 10 & 17 \\
\hline 5 & 5 & 16 & 13 \\
\hline 6 & 4 & 15 & 15 \\
\hline $7 a$ & 9 & 6 & 19 \\
\hline $7 \mathrm{~b}$ & 0 & 9 & 25 \\
\hline
\end{tabular}

type works are those that could favor the development of conceptual and procedural skills for the understanding of the articulated concepts of function and quadratic equation at the pre-university level.

In relation to students who train for mathematics teachers, it has been identified in the literature that they present limitations of mathematical content mastery, for example, they do not have the conceptual understanding of function and quadratic equation, particularly of the concept of parabola and about quadratic transformations, in addition, only some mastery of algorithmic processes associated with the concept is identified in them (Mosquera \& Uzuriaga, 2018).

As documented above, there are different problems around the concepts of function and quadratic equation that influence their understanding, these problems are identified at the secondary and pre-university levels, and it is likely that these situations are a factor for university students to present problems of appropriation of these concepts, preventing them from understanding content taught at these levels related to precalculus, calculus, among others. One of the main reasons why these problems persist may be due to the fact that at the secondary and pre-university level, generally the concept of a function and quadratic equation is taught as algebraic manipulation of equations, based on specific methods and standardized exercises (Gustin \& Avirama, 2014). This results in difficulties for students to move from the graphical representation of the concept to the algebraic one, the absence of skills to apply the concept to problem-solving (via interpretation, model construction, and its resolution).

\section{Difficulties on the Quadratic Function and Equation Identified in Students Aspiring to a Bachelor's Degree in Mathematics at a Public University in Mexico}

The above mentioned investigations and the results found in them, on diverse problems identified both in students and teachers about the quadratic function and equation in the different school levels, motivated to investigate in the local environment in students aspiring to the career of Bachelor in Mathematics who come from different educational subsystems of upper secondary level (students aged 16-18 years), of the state of Guerrero, Mexico, about what is their mathematical domain about the indicated content. For this purpose, a questionnaire was elaborated and applied to a group of thirty-four students, at the time of the application of the questionnaire this population was about to start the introductory course to the mathematics program.

The questionnaire was structured into seven activities, as indicated below:

1. Write the definition of a quadratic equation.

2. What does it mean to you to solve a quadratic equation?

3. Which methods for solving quadratic equations do you know? Describe one method.

4. What is the discriminant and what information does it provide when solving a quadratic equation?

5. Write the definition of a quadratic function.

6. What is the relationship between the solutions of the quadratic equation and the behavior of the quadratic function?

7. Solve the following problems:

a. Two positive integers differ by 6 units, and the sum of their squares is 218 . What are these two numbers?

b. One faucet takes 2 hours longer than another to fill a tank and opening both together fills it in 1 hour and 20 minutes. How long will it take to fill each of the faucets separately?

The questionnaire was answered individually in a time of 1 hour and 40 minutes; Table 1 shows the concentration of responses. As shown in Table 1 , in relation to activity 1 , most of the students have a misconception about the definition of quadratic equation, within this type of answers the following were identified:

1. Polynomial variable function.

2. Equation formed by monomials with exponent 2 .

3. It is an equation squared.

4. It is an expression of the form $a^{2}+2 a b+b^{2}=0$.

5. Of the form of a parabola.

According to these productions of answers, it can be inferred that this group of students does not have developed the ability of the definition of quadratic equation, this may be due to the intuitive character of the treatment of most of the contents taught in the pre-university. As indicated, only three students established the definition, twenty-four answered equivocally and five of them did not provide any answer. In relation to question 2, six students mentioned that solving an equation means determining the values of the variable $x$, twenty-four of them gave equivocal answers, such as: graphing, tabulating, analyzing behavior, trying 
the general formula for equations of degree two, among other answers, while four students did not answer. As can be identified, this variety of equivocal answers reinforces the hypothesis that commonly the intuitive work and the neglect of the conceptual part can generate this range of non-formal ideas around the definition and solution of mathematical models that are associated with this type of equations.

About activity 3 , it is striking that most of this group of students have solved quadratic equations, unlike the majority who do not know the meaning of solving a quadratic equation. As identified in the answers, of sixteen students who have solved equations, five of them know as a method of solving: "the general formula for solving equations of degree two", seven students know two methods: "the general formula for solving equations of degree two and by the method of graphing", while four students know three methods: "the general formula for solving equations of degree two, graphing and the completeness of perfect squares". None of the students mentioned factoring as a way to solve this type of equations, these findings, possibly are an indicator that in the teaching activity of the quadratic function and equation, the forms are incorporated as a teaching object $y=a x^{2}+b x+$ $c, y=(a(x-r)(x-s))$ and the form $y=a(x-h)^{2}+h$, since according to Wilkie (2022)

"the study of these forms of the equation, can help to go beyond memorization about particular cases and identify that generalization processes can contribute in the understanding of this content".

In relation to activity 4, eight students know what discriminant is, they identify how it is formed, but it is difficult for them to explain what information it provides to know whether or not there is a solution to the equation, nor did they indicate how it helps to know about the graph of the equation. On activity 5, five students answered correctly and established that the quadratic function is of the form $f(x)=a x^{2}+b x+c$, while sixteen students have an unfinished idea (classified as an incorrect answer) and thirteen did not answer. In sum, twenty-nine students have the difficulty in recognizing and writing the form of the quadratic function.

On the relationship of the equation and quadratic function (activity 6), four students established that both are of degree two, the solutions of the equation are points of intersection of the curve with the horizontal axis. Note that they did not establish the relationship when there is a solution of multiplicity two and when there are complex solutions. This reduced number of students who answered correctly shows the need to integrate the contents for their treatment (since they are directly related) and to discard the possibility of disjoint treatment.

In relation to the first problem of activity 7 , nine correct answers were identified, however, only one description of the solution was identified, and it shows the construction of the quadratic equation as a mathematical model. Of the eight answers that did not describe any method, it is intuited that they proceeded by trial and error. Of the second problem that was proposed, no solutions were identified, which means that the students have not developed the ability to solve problems in which they put into play the equations of degree two.

As has been documented in the reference research and in the exploration with students entering university studies, the various problems related to the teaching and learning of the quadratic function and equation, essentially at the high school level, yield elements that make it necessary to search for alternatives that have an impact on these processes. Therefore, the following question naturally arose: What didactic strategies favor the process of understanding the quadratic function and equation in preuniversity students? And as an objective of this work, it was projected: the elaboration of a hypothetical learning trajectory proposal of theoretical-didactic character for the understanding of the quadratic function and equation in the pre-university.

\section{THEORETICAL AND METHODOLOGICAL FOUNDATIONS}

In this work it is assumed that the treatment of mathematical concepts, particularly the articulated concepts of function and quadratic equation, is enriched through the incorporation of semiotic representation registers, particularly graphic, numerical and algebraic registers as favorable scenarios to influence the understanding of the definition and properties surrounding these concepts. The specific activities planned in this work require the use of different registers of semiotic representation for their study. The use of GeoGebra software is fundamental, since this technological tool favors the dynamic-visual activity, which makes it possible in each of the semiotic representation registers to favor the study of the variational ideas that affect the development of understanding.

These ideas are structured in a hypothetical learning trajectory proposal of the articulated concepts of function and quadratic equation. The importance of this hypothetical learning trajectory lies in the consideration of the learning objectives; which obliges the teacher-researcher to elaborate proposals for the direction of teaching and learning, in the selection of the mathematical tasks that will be proposed; which requires having a solid formation and mastery of mathematical content, which allows the choice of key tasks and their treatment to favor understanding. The consideration of the hypothetical character lies in the fact that any route or approach for learning purposes, the success of it, depends largely on the nature of the student. Specifically, in this work we propose some different routes to the classical presentation of teaching and learning treatment, based on variations of ideas to influence the understanding of the articulated concepts of function and quadratic equation.

\section{Understanding Mathematical Concepts}

Concepts are part of the mathematical structure and play a fundamental role in the development of mathematical knowledge and in the explanation of objective reality (Ballester, 1992). A large part of the difficulties in the understanding of mathematical content documented in the research lies in the absence of the treatment of concepts. In this work it is assumed that the understanding of concepts requires two fundamental activities: formation and assimilation (fixation) (Morales \& Damián, in press). 
Under this perspective, the present research seeks to contribute resources to influence the understanding of the articulated concepts of function and quadratic equation, through the study of problems that involve variational ideas.

The research works of Morales et al. (2014) and Arteaga et al. (2009) coincide in assuming that the understanding process requires exercises, deepening, systematizations and applications of the concept. Therefore, the following stages must be methodologically developed in order to make this understanding process possible: Approach to the concept. In this stage, the essential features and conditions that come into play in the definition of the concept are recognized. Formalization of the concept. The formalization of the concept encompasses the previous stage and is essentially aimed at favoring the assimilation of the concept definition, therefore, the following are considered: approximation, formalization, evaluation and control as fundamental stages of this process. Identification of the concept. In this phase some problems are proposed that favor the identification of the need to use the concept. Application of the concept. In this stage, problems are analyzed that favor assimilation through application and therefore contribute to conceptual understanding.

In each of the stages of the understanding process, heuristic procedures are a fundamental tool, since they constitute mental search resources that allow orienting and contributing elements for the understanding and determination of the concept on the basis of problem-solving (Torres, 2013).

\section{Theory of Registers and Semiotic Representations}

Duval $(2004,2016)$ states that learning mathematics is a field conducive to the study and development of important cognitive activities such as conceptualization, reasoning, problem-solving and text comprehension. Thus, teaching and learning mathematics requires that these cognitive activities require, in addition to natural language or images, the use of different registers of representation and expression. The researcher establishes that semiotic type representations constitute the only means of access to mathematical objects, which raises the cognitive problem "of the recognition of the object in different registers of representation and of the passage from the representation of an object to another representation of that same object." Furthermore, he explains that throughout the history of the development of mathematics it was identified that the development of semiotic representations was an essential condition to favor the development of mathematical thinking, therefore, it is agreed that mathematical strategies intrinsically imply the transformation of a semiotic representation.

Duval (1993, 2006, 2016) highlights two essential transformations that influence the development of conceptual understanding: treatment and conversion.

\section{Treatments}

These are representations that occur within the same register; for example, performing a calculation while remaining strictly in the same notation system to represent numbers, solving an equation or system of equations, completing a figure using perceptual criteria of connectivity or symmetry.

\section{Conversions}

These are representational transformations that consist of changing a register without changing the denoted objects; for example, going from the algebraic notation for an equation to its graphical representation, going from the statement of a relation in natural language to its notation using letters, among others. Conversion, which is a transformation in representation, is more complex than processing because any change of register first requires that between two representations whose contents often have nothing in common, the same represented object is recognized. Thus, it is justified that thought processes in mathematics are based on the two types of transformations of representations, even if a single register of representation is sufficient from a mathematical point of view, since, from a cognitive point of view, mathematical activity involves the simultaneous mobilization of at least two registers of representation, or the possibility of changing at any time from one register to another.

\section{Hypothetical Learning Trajectories (HLT)}

Simon and Tzur (2004) identify the main characteristics of the notion of hypothetical learning trajectory as follows: A hypothetical learning trajectory (HLT) consists of goals for student learning, mathematical tasks used to promote learning, and hypotheses about the learning process. In this direction, researchers such as (León et al., 2014) agree that THAs refer to the teacher's predictions about the path along which learning can be mobilized, are hypothetical due to the fact that the actual trajectories of students' learning depend on the conditions of existence of each individual and on the fact that individuals' learning has certain regularities. In addition, they establish that the THA provide the researcher with a rational criterion for deciding the design to be considered and the conjectures of how to make learning evolve.

The elaboration of the hypothetical learning trajectory must contemplate all the elements that support it as a construct: understanding of the current knowledge of the students who will receive the instruction, description of fundamental aspects of assimilation and fixation, the selection of tasks, and the mathematical and methodological preparation of the teacher for possible intervention, in case it is necessary to modify some aspect of the THA. With the implementation of the Hypothetical Learning Trajectory, the student's cognitive development is affected, so it is important to carry out its analysis in a first stage, so that the teacher can describe his hypotheses about how students can progress in the construction of their knowledge about the mathematical structure, when they face tasks about the mathematical object of interest (Gómez \& Lupiañez, 2007).

\section{GeoGebra Software}

Morales and Damián (in press) state that this software is part of the technological tools, it is a software that favors the dynamicvisual activity and that makes possible through the tools it offers the treatment of mathematical contents in the different educational levels. 
The researchers cited argue that the use of GeoGebra as a heuristic tool makes it possible to evolve the processes that have generalization; this is through the rediscovery of behavioral patterns. They argue that the software alone does not provide the solutions to different situations; it is as it is manipulated, tested or as pre-elaborated or theoretically valid actions are carried out that these processes are rediscovered, conjectures are formulated, resolution strategies are proposed and these processes are carried out. In this sense, the dynamic-visual representation and its treatment favored by the software makes it a heuristic resource for the teaching and learning of algebra, geometry and calculus in particular. With the aforementioned, in this work we will assume GeoGebra software as: "a heuristic resource mediator of the teaching and learning processes, where the dynamicvisual activity that favors as the association of images-ideas contributes in the internalization of the processes of abstraction on the mathematical contents to be treated and that influence mathematical understanding".

\section{METHODOLOGY}

As described above, this work is of a theoretical-didactic nature and aims to influence the understanding of the concepts of function and quadratic equation in pre-university students.

\section{Hypothetical Learning Trajectory Proposal and Its Validation}

The proposal was structured in seven levels, in each of them activities related to the quadratic function (problem type) were proposed, these activities involve variational ideas and their treatment contributes to the attention to the understanding processes of concepts that were established in the theoretical foundation. The proposal was validated through the criterion of experts, following this validation methodology; at the end, six experts were considered: all of them with doctorate degree, more than five years of experience in teaching and research, and specialists in mathematical analysis and didactics of mathematical analysis, besides, five of them are involved in pre-university and university levels, and one of them, only in the university level.

\section{Validation Questionnaire}

It consisted of six central questions whose main objective was to validate the proposal, as follows:

1. Do you consider that the proposal is suitable for implementation with pre-university students?

2. In the proposed activities, is the mathematical content of the concepts of function and quadratic equation identified?

3. Is the theoretical and methodological foundation of this proposal adequate?

4. Is the development of the understanding of the concepts of function and quadratic equation through variational ideas identified? Is the role played by GeoGebra software in the treatment of the function and quadratic equation, through the variational approach, identified?

5. Does the proposal of activities resemble a classical presentation as provided by the reference texts? Do you identify any differences?

6. What improvements from the mathematical point of view are essential?

\section{Validation Results}

The six experts considered the proposal to be adequate; the answers they gave helped to improve the formulation and relationship of the activities that make up the proposal. In addition, the validation process made it possible to redefine the mathematical content that is favored when developing the activities.

\section{DISCUSSION AND RESULTS}

The following is a description of the specific activities at each of the levels that make up the proposal. In each case, a discussion is made at the theoretical-didactic level, and finally, the respective conclusions are drawn.

\section{Level 1. Construction of the Concept by Means of Covariational Ideas Using GeoGebra}

In this level a particular case of the behavior of the orthogonal relation $p=d^{2}$ (the product of two equal lengths) is shown. That is, if the length $d$ changes values between positive, then how can the value of $p$ be affected? Figure 1 shows the case where $d=1.4$ (note that since $d=\overline{O A}$ and by the definition of the points $O$ and $A, a=d$; therefore, $p=(1.4)(1.4)=(1.4)^{2} \approx 1.96$.

Here the didactic impulse refers to the question: What changes when $d$ changes? It is expected that the actors (teachers or students) identify that if $d$ changes, the orthogonal segment $p$ also changes, and increases or decreases according to the variation of values of $d$. From the evidence that the orthogonal segment $p=A T$ changes as $d$ does, the question is prompted: What form does the trajectory of $T$ acquire as $d$ changes? Figure 2 shows the case of the trajectory of the point as $d$ acquires positive values, it can be seen that the trajectory generated by the path of the point $T$ is not of linear type, in this case, a quadratic type behavior is visualized. 


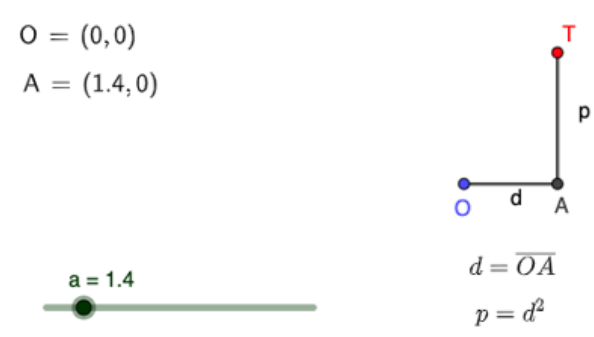

Figure 1. Particular representation of the orthogonal relation (Source: own elaboration)

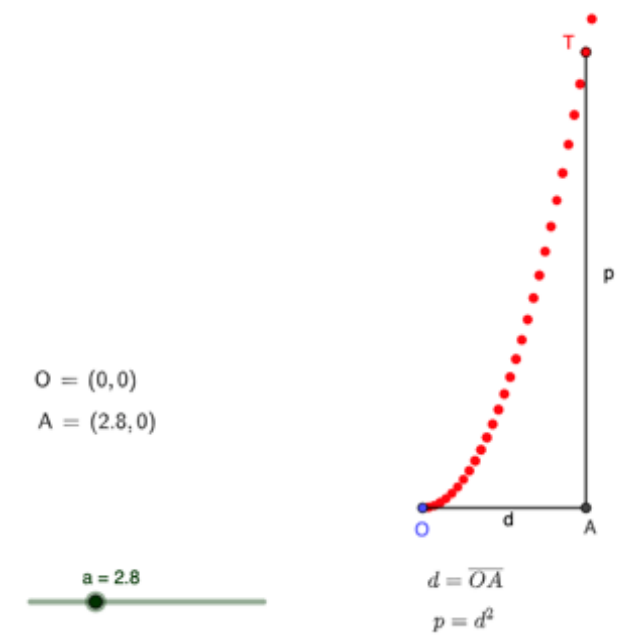

Figure 2. Representation of the trajectory of point $T$ (Source: own elaboration)

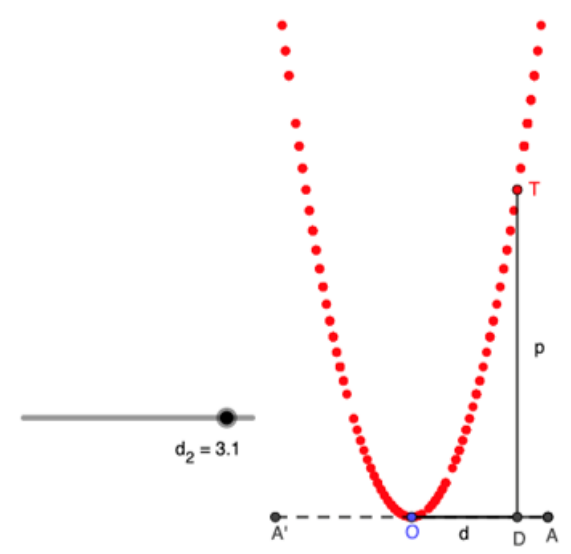

Figure 3. Representation of the trajectory of point $T$ as $d$ varies between negative and positive values (Source: own elaboration)

\section{Level 2. Generalization Principle}

At this stage the actors consider the above behaviors whenever $d$ takes positive values (starting from (0) to the right) and negative values (starting from (0) to the left). In Figure 3, it can be identified that $p$ changes conditional on the change of $d$. By varying $d$ between negative and positive values, $T$ makes the path in a quadratic type trajectory, always decreasing when $d$ moves from left to right to zero and always increasing when $d$ moves from left to right starting from zero.

Level 3. Intermediate Stage Between the Construction of the Orthogonal Relation Graph in the Euclidean Plane and Its Treatment in the Cartesian System

In this stage the graph is constructed as a geometric locus, without neglecting the study of the behavior of covariational relationships. However, in this case the orthogonal relationship between the segments that condition the point $P$ are in dependence of the variation of a point that moves along the directrix. This stage is fundamental since through the use of the software, in the construction of the graph as a geometric locus; the algebraic view patents the analytical-algebraic expression of the equation of the geometric locus (this equation is a particular case of the general equation of second degree). What is relevant in this process is the passage to the representation and treatment of the covariate relations that make possible the geometric 


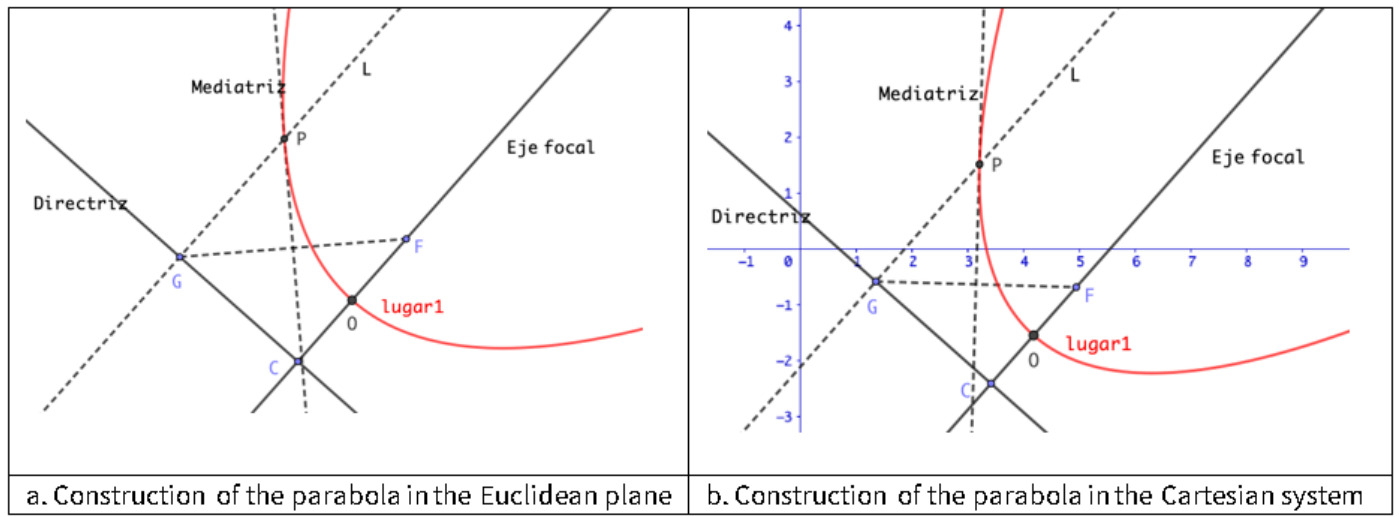

Figure 4. Graphical representation of the covariational relationship in the Euclidean plane and in the coordinate system (Source: own elaboration)

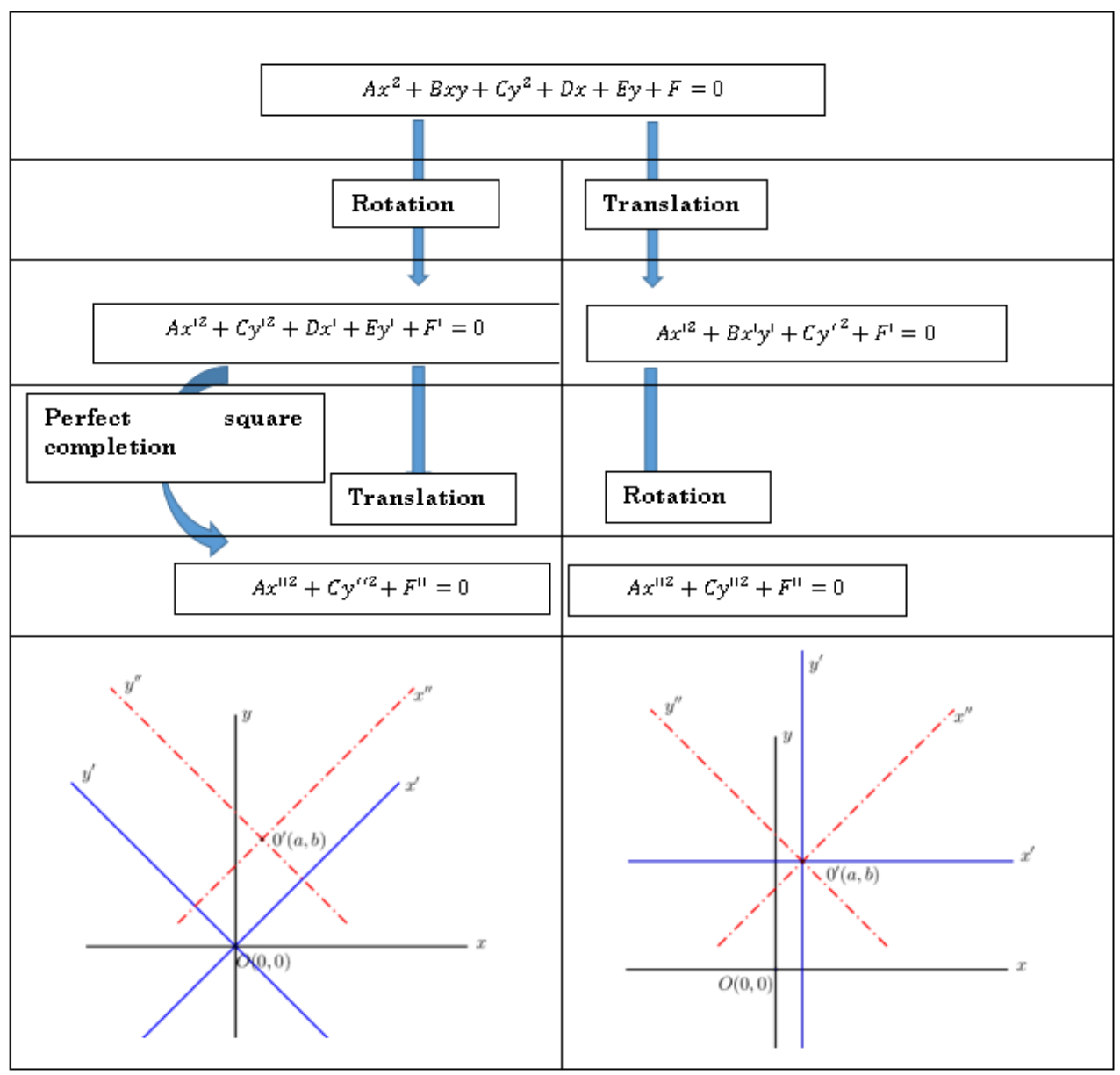

Figure 5. Effects of translation and rotation to the second degree equation (Source: own elaboration)

locus in the coordinate system (Figure 4). In this new system of representation favors the introduction of the elements of the curve and its determination.

It is wise to emphasize that naturally, and during the heuristic development of the study of the composition of the orthogonal relation involving covariational reasoning, the associated equation appears in the process of construction of the geometric locus, which is a case of the general equation of second degree $A x^{2}+B x y+C y^{2}+D x+E y+F=0$.

It has been found that commonly in practice it has not been of interest to study equations given in the above form. However, Morales (2016) emphasizes that it is important this study in pre-university. In this regard, he proposed a strategy in which he showed the potential of the isometric transformations of the plane: translation and rotation to transform the equations of second degree and with this, facilitate their graphical representation. The following scheme shown in Figure 5 describes the role of the isometric transformations to eliminate the mixed term $B \times y$, then take the equation to the canonical form; in such a way that its graphical representation is facilitated. 


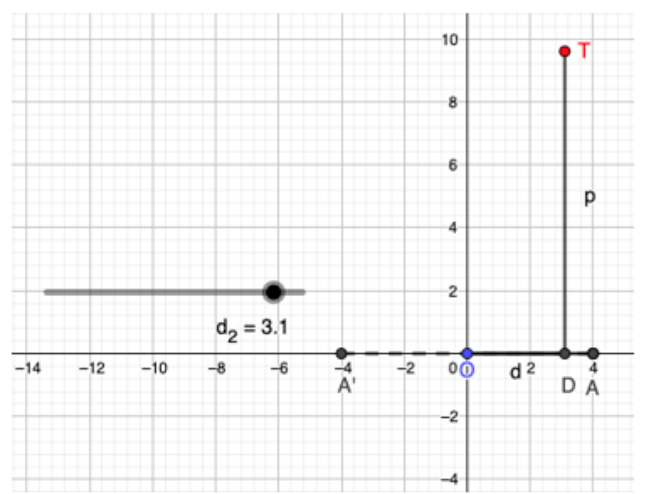

Figure 6. Representation of the phenomenon of variation in the coordinate system (Source: own elaboration)

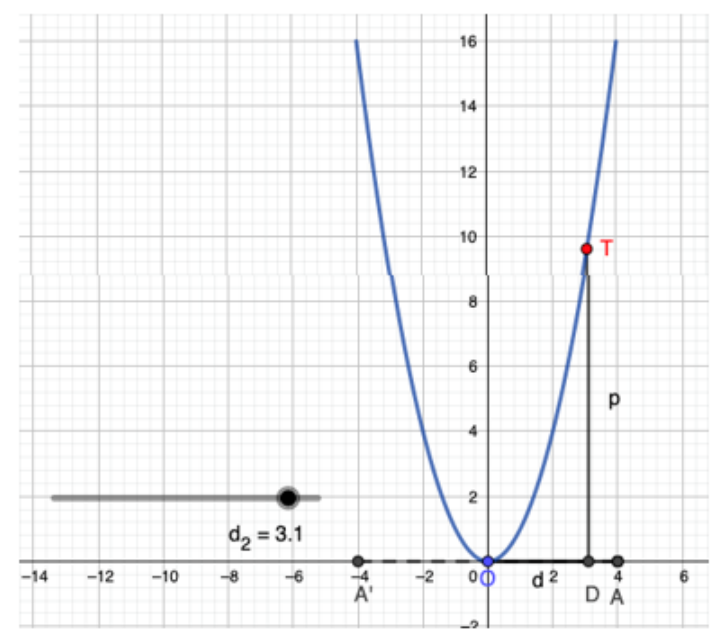

Figure 7. Curve associated with the quadratic function (Source: own elaboration)

With the activities carried out in the geometric register and the transition to the treatment in the Cartesian system, the conditions for the study of the orthogonal relationship between segments in the coordinate system have been created and with it, the step to the treatment of the definition of the quadratic function. Figure 6 represents the main situation "behavior of the orthogonal relation of two varying maginutes" in the Cartesian system.

Putting the situation in this register, the behavior of point $T$ is analyzed, in the same way it is identified that the trajectory that this point follows depends on the variation of $d$.

\section{Level 4. Functional Relationship of Orthogonally Varying Magnitudes}

It has been observed that the changes of $p$ depend on the change of $d$. By taking this behavior to a coordinate system, the functional relationship $y=x^{2}$ can be noted, this is naturally possible in the dynamic process that has been anticipated. Figure 7 shows the curve associated with the quadratic function, this curve represents the locus of point $T$ as $d$ moves through positive and negative values. It is immediately rediscovered that such behavior is also acquired when plotting the quadratic function $y=x^{2}$.

Level 5. Analysis of the Functional Relation $p=d^{2}$ and $f(x)=x^{2}$. Definition of the Quadratic Function and Its Graph

Considering the particular case studied, the actors now analyze and induce the generalization of the algebraic, graphical, and analytical form of the quadratic function. From this point on, it is possible to redefine graphically the concepts of increasing, decreasing and stable, since the behavior of $f(x)=x^{2}$, although represented by a parabola, can be understood as the variation already described up to now, depending on its slope, of a point $(x, f(x))$ that moves smoothly, and that can be increasing, decreasing or stable, thus introducing the additional concepts of maxima, minima, and inflection points, aspects that better characterize curves of degree greater than one.

\section{Level 6. Concept Fixation}

At this level, problem-type situations are promoted that require the construction of the quadratic function and its analysis in order to be solved. As an example, two situations are described in the following.

\section{Situation 1. Vertical free fall of a body}

Figure 8 represents the process of vertical free fall of a body from a height of $300 \mathrm{~m}$. What is interesting here is to show the pre-university student situations whose graphical behavior is not of a linear type, in this case of a quadratic type, and that it is 


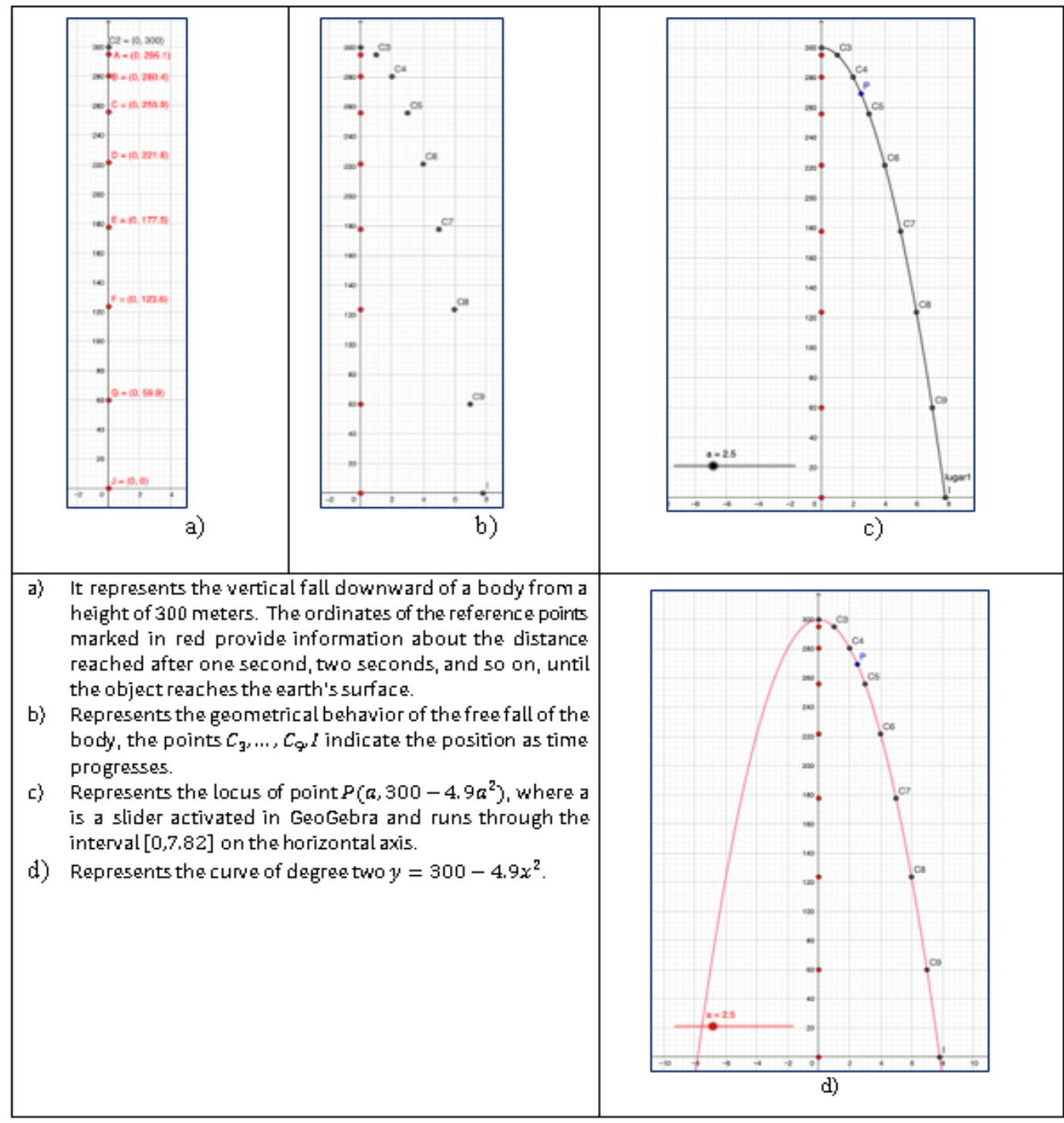

Figure 8. Process of constructing a graphical model of the fall of a body (Source: own elaboration)

necessary to learn the quadratic because of the role it plays inside and outside mathematics. This will require, at a later stage, the formal presentation of the concept, its definition and its axiomatic treatment.

\section{Situation 2. Divide a segment of 7 units in length into two}

In this situation, divide a degment of 7 units in length into two not necessarily equal parts, such that the product of the lengths of the two subsegments that divide it is the maximum. In a dynamic geometry environment made possible by GeoGebra software, a segment of length 7 units is drawn. A point (not fixed) is placed on the segment and the two dividing sub segments are drawn. It is identified that as the movable point traverses the main segment, the product of the lengths of the division sub segments varies, and it is intuited that the appropriate position of the movable point should be in the vicinity of the center of the main segment, in order to achieve the maximum product. This visualization is also supported by constructing and observing the behavior of the area of a rectangle whose dimensions are the lengths of the sub segments. It is observed that as the point approaches the center of the main segment, the figure tends to be a square, and that the product associated with the area is the maximum.

The geometric locus of the area is constructed as the movable point travels along the segment. At first the manual work is done with the software and from this activity the general behavior is induced.

Finally, it is discovered that the measures of the lengths of the sub segments that make their product the maximum are equal. Generalization principle: The mathematical model (quadratic function) of the situation is constructed. This is possible because three points are known: $(0,0),(7,0)$, and $(a, c 1)$ where $a$ is a slider that runs along the segment $\overline{A B}$ of 7 units, and $c 1$ indicates the product of the lengths of the sub segments. A point is located on the curve, and a tangent is constructed through that point. This activity is done with the purpose of relating the intuitive work being developed with the tools offered by analytical geometry. It is observed that as the abscissa of the tangent point approaches from the left to the abscissa of the midpoint of the main segment, the tangent has an increasing behavior, for values in a neighborhood of the midpoint the tangent tends to have a horizontal behavior, if the abscissa of the tangent point is to the right of the abscissa of the point in the main segment the tangent has a 


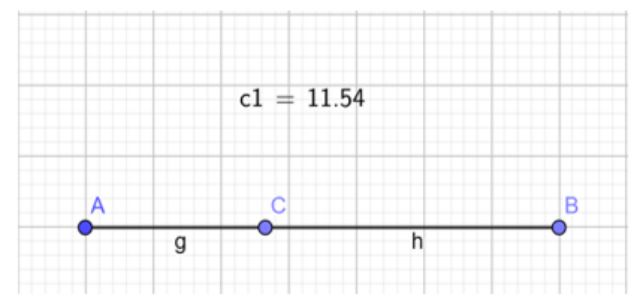

Figure 9. Representation of the problem situation (Source: own elaboration)

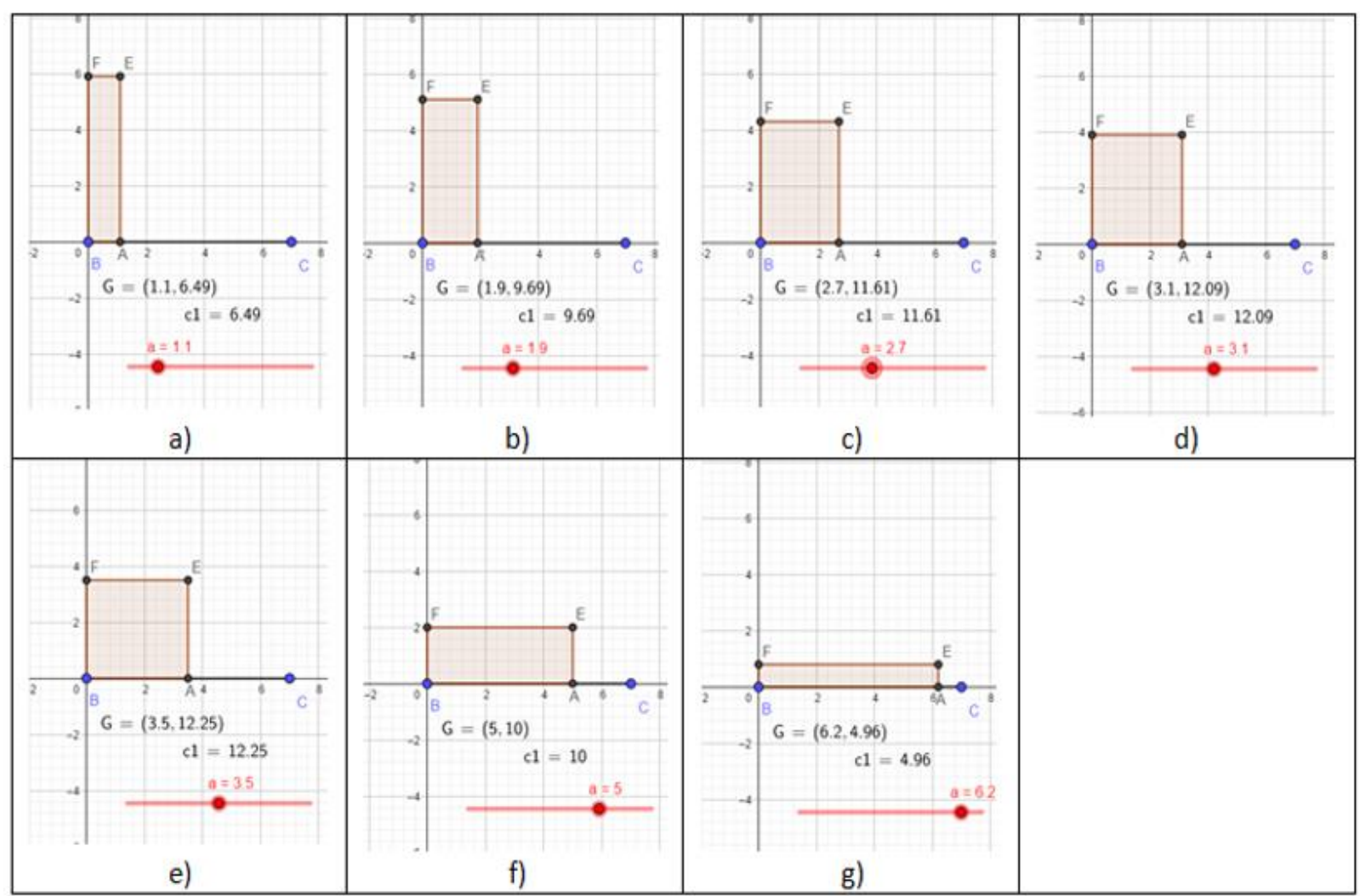

Figure 10. Representation of cases of variation of area measurement (Source: own elaboration)

decreasing behavior. This identification is done by using the software, and a criterion for the investigation of the maximum of a function is induced, based on the criterion of the first derivative.

\section{Development of the Actions Using GeoGebra Software}

1. Point $C$ has been located on the segment, the dividing sub segments are $\overline{A C}$ and $\overline{C B}$. The product of the lengths of the sub segments we denote by $c 1=(\overline{A C})(\overline{C B})=11.54$ (Figure 9).

2. The value of $c 1$ changes as point $C$ traverses the main segment, as stated in the previous step, as the movable point approaches the center of the segment, the product grows to its maximum value and tends to decrease as the point approaches the right end of the segment. With the purpose of identifying and conjecturing about the measures of the sub segments that satisfy the conditions of the problem, a rectangle was constructed by taking pairs of measures (consider that the pairs of measures are variable, since they are conditioned in this case by the path of point $A$ in the segment $\overline{B C}$ ) and thus as point $A$ varies, the measures of the area change as shown in Figure 10. 


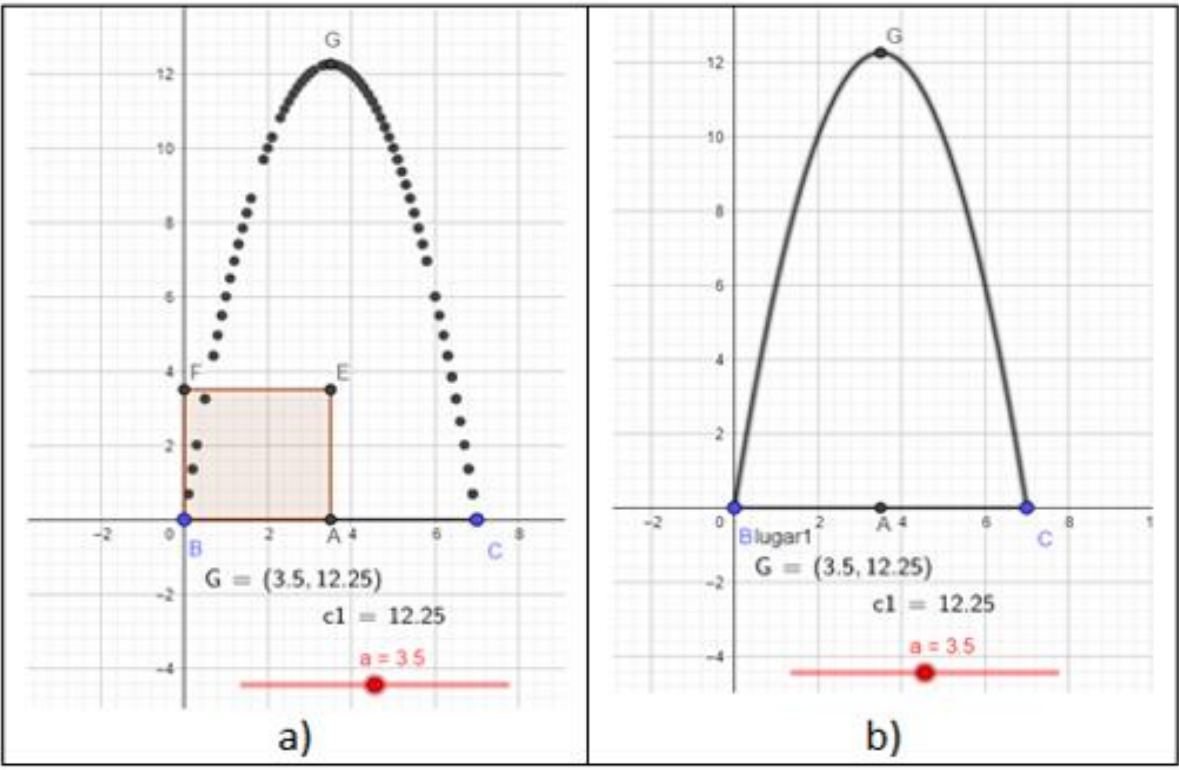

Figure 11. Graphical representation of the variation of the area (Source: own elaboration)

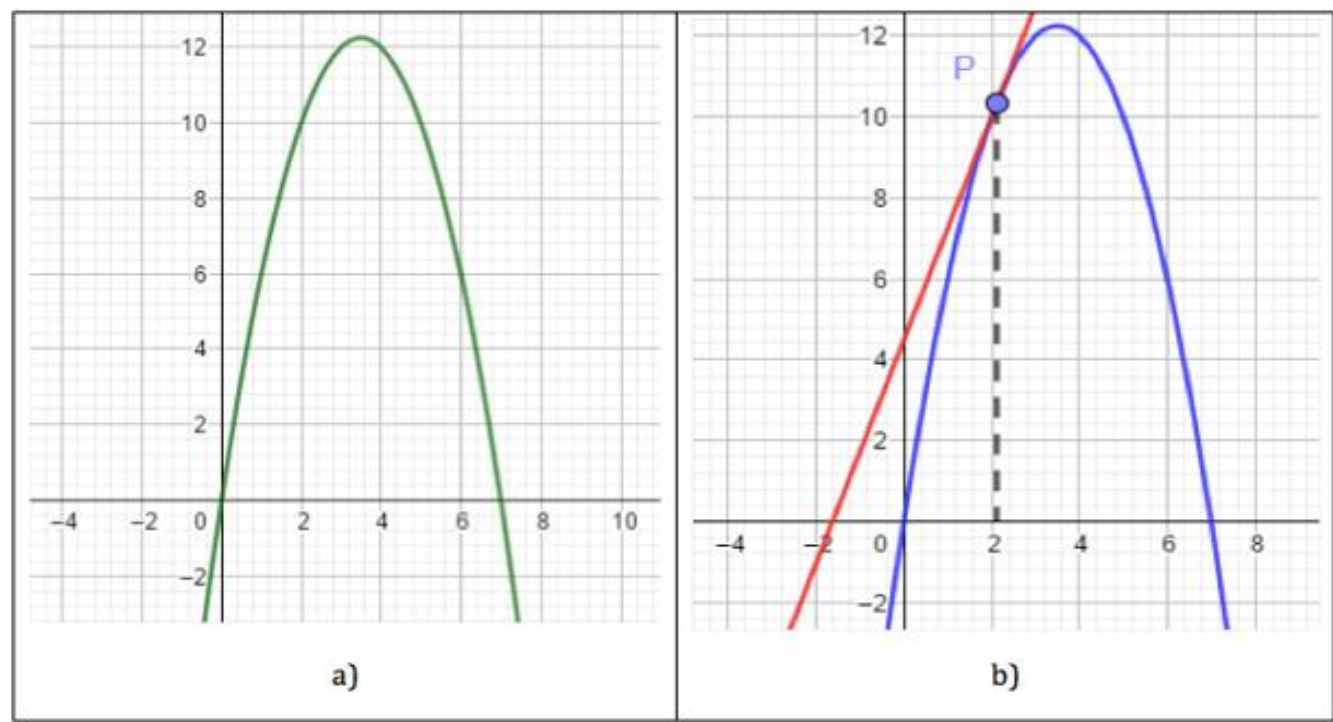

Figure 12. Graphical representation of the tangent on the curve representing the situation (Source: own elaboration)

3. Geometric location of the situation. In Figure 11, a) it is observed that making point $A$ traverse the segment $\overline{B C}$ describes in the plane the geometric locus. In Figure 11, b) such geometric locus has been formally constructed, and it is identified that the largest image is reached when point $A$ is in a neighborhood of the center of the segment, and makes the figure tend to be a square. With the above analysis, it is concluded that the lengths of the sub segments that make the product the maximum should be equal.

4. Construction of the mathematical model (curve of degree two) passing through three points: $f(x)=-x^{2}+7 x$, its graph and the tangent to it, at the indicated point as shown in Figure 12.

Figure 13 shows that the tangent tends to have a horizontal behavior when the abscissa of the tangent point tends to the neighborhood of the center of the main segment. That is, the behavior of the tangent helps to discover and systematize the maximum value of the function, therefore, the measures of the lengths of the sub segments that make the product maximum. 


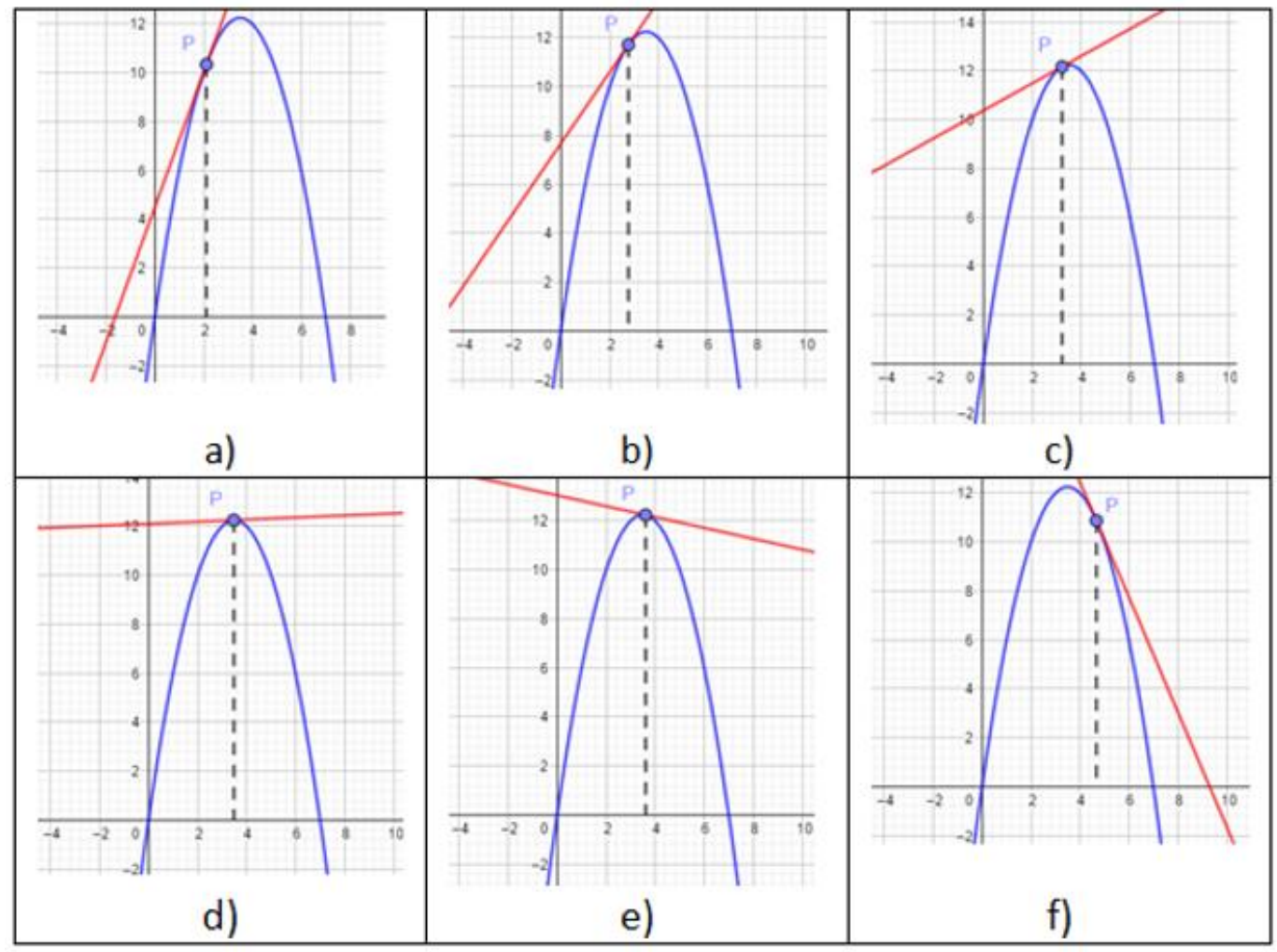

Figure 13. Variation of the tangent and identification of the relative maximum (Source: own elaboration)

Through the use of GeoGebra software, the identification of the position of the movable point in the segment was favored, this at the same time, allowed to determine the lengths of the two sub segments of division and to guarantee that the product is the maximum. Another way was to identify the behavior of the: tangent on the curve that represented the area of the rectangle, by varying the point it was observed that the tangent point changed its position on the curve and therefore the tangent. From this last behavior, it was identified that at the point of maximum the tangent is horizontal (zero slope), and before and after the point on the abscissae, it grew and then decreased. This identification allowed two situations:

1. Identify a first approach to the derivative criterion for investigating relative maximum and/or minimum of a function.

2. To give an introduction to the analysis of the variation of functions.

\section{Level 7. Formal Presentation of the Content and Its Axiomatic Treatment}

Finally, the development of the previous levels provides the elements of significance that contribute to the assimilation of the concepts of function and quadratic equation. At this level, it is natural to formally introduce the definitions and properties of the concepts under study, their treatment and their applications.

\section{GENERAL CONCLUSIONS}

This proposal is based on variational ideas and their treatment through the use of GeoGebra software and aims to favor the process of understanding the quadratic function and equation, this hypothetical learning path for the study of these concepts in pre-university presents the following characteristics: it breaks with the classical scheme of presentation of the content and incorporates variational ideas and the use of dynamic software; which favors the transition from the dynamic approach to the static approach in the treatment of the content, with this elaboration it contributes in the attention to the difficulties found in preuniversity students about the notion of function and quadratic equation, it implements a non-recurrent path that contributes in the attention to the search for meanings as part of the process of understanding of these concepts.

Author contributions: All authors have sufficiently contributed to the study, and agreed with the results and conclusions.

Funding: No funding source is reported for this study.

Declaration of interest: No conflict of interest is declared by authors. 


\section{REFERENCES}

Arias-Rueda, J, H., Arias-Rueda, C. A., \& Burgos Hernández, C. A. (2020). Procesos aplicados por los estudiantes en la resolución de problemas matemáticos: Caso de estudio sobre la función cuadrática [Processes applied by students in solving mathematical problems: Case study on the quadratic function]. Góndola, Enseñanza y Aprendizaje de las Ciencias [Gondola, Science Teaching and Learning], 15(1), 284-302. https://doi.org/10.14483/23464712.14614

Arteaga, E., Díaz, A., García, F., \& del Sol, J. L. (2009). Alternativas metodológicas para la formación y fijación de conceptos geométricos en la geometría plana [Methodological alternatives for the formation and fixation of geometric concepts in plane geometry]. Quaderns Digitals: Revista de Nuevas Tecnologías y Sociedad [Quaderns Digitals: Magazine of New Technologies and Society], 60, 1-25.

Ballester, S. (1992). Metodología de la enseñanza de la matemática I [Mathematics teaching methodology I]. Editorial Pueblo y Educación [Editorial People and Education].

Cetina, M., Cabañas, G., \& Villa- Ochoa, J. (2016). La función cuadrática y su proceso de matematización [The quadratic function and its mathematization process]. Investigación e Innovación en Matemática Educativa [Research and Innovation in Educational Mathematics], 1(1), 41-48.

Duval, R. (1993). Registres de représentation sémiotique et fonctionnement cognitif de la pensée [Registers of semiotic representation and cognitive functioning of thought]. Annales de Didactique et de Sciences Cognitives, IREM de Strasbourg, Francia [Annals of Didactics and Cognitive Sciences, IREM of Strasbourg, France], 5(1), 37-65.

Duval, R. (2004). Semiosis y pensamiento humano: Registros semióticos y aprendizajes intelectuales [Semiosis and human thought: Semiotic registers and intellectual learning]. Universidad del Vale, Instituto de Educación y Pedagogía [Universidad del Valle, Institute of Education and Pedagogy].

Duval, R. (2006). A cognitive analysis of problems of comprehension in a learning of mathematics. Educational Studies in Mathematics, 61(1-2), 103-131. https://doi.org/10.1007/s10649-006-0400-z

Duval, R. (2016). Un análisis cognitivo de problemas de comprensión en el aprendizaje de las matemáticas [A cognitive analysis of comprehension problems in mathematics learning]. In R. Duval, \& A. Sáenz-Ludlow (Eds.), Comprensión y aprendizaje en matemáticas: Perspectivas semióticas seleccionadas énfasis [Understanding and learning in mathematics: Selected semiotic perspectives emphasis] (pp.61-94). Universidad Distrital Francisco José de Caldas [University Francisco Jose de Calda].

Genicio, M., Lazarte, G., Porcinito, S., \& Hernández, C. (2005). Ecuación cuadrática: Una ingeniería didáctica para su enseñanza [Quadratic equation: A didactic engineering for its teaching]. In J. Lezama, M. Sánchez, \& J. Molina (Eds.), Acta Latino Americana de matemática educativa 18 [Latin American educational mathematics act 18] (pp. 93-99). Comité Latinoamericano de Matemática Educativa [Latin American Committee for Educational Mathematics].

Gómez, P., \& Lupiáñez, J. L. (2007). Trayectorias hipotéticas de aprendizaje en la formación inicial de profesores de matemáticas de secundaria [Hypothetical learning trajectories in the initial training of high school mathematics teachers]. PNA, 1(2), 79-98.

Gustin, J., \& Avirama, L. M. (2014). Una propuesta para la enseñanza de la ecuación cuadrática en la escuela a través de la integración del material manipulativo [A proposal for the teaching of the quadratic equation in school through the integration of manipulative material] [Undergraduate thesis, Universidad del Valle-Valley University].

Haruna, M. (2015). Analysis of problem-solving difficulties with quadratic equations among senior secondary school students in Zaria, Nigeria. Journal of Science, Technology \& Education, 3(3), 1-10.

Hau-Yon, F., \& Zapata, M. (2019). Conocimiento didáctico del contenido de la función cuadrática en estudiantes para profesor de matemáticas [Didactic knowledge of the content of the quadratic function in students for a mathematics teacher]. In J. M. Marbán, M. Arce, A. Maroto, J. M. Muñoz-Escolano, \& A. Alsina (Eds.), Investigación en educación matemática XXIII [Research in mathematics education XXIII] (pp. 383-392). Universidad de Valladolid [University of Valladolid].

León, O. L., Díaz, F., \& Guilombo, M. (2014). Diseños didácticos y trayectorias de aprendizaje de la geometría de estudiantes sordos, en los primeros grados de escolaridad [Didactic designs and geometry learning trajectories of deaf students, in the first grades of schooling]. Revista Latinoamericana de Etnomatemática [Latin American Journal of Ethnomathematics], 7(2), 9-28.

Manrique, J., Gallo, A., \& Gallardo, H. (2017). Estado del arte alrededor del concepto de función [State of the art around the concept of function]. In R. Prada-Núñez, P. Ramírez, C. Hernández, H. Gallardo, S. Mendoza, \& G. Rincón (Eds.), Encuentro internacional en educación matemática [International meeting on mathematics education] (pp. 157-164). Universidad Francisco de Paula Santander [Francisco de Paula Santander University].

Morales, A. (2016). Propuesta didáctica para la enseñanza de la traslación de coordenadas y su uso en la graficación de curvas [Didactic proposal for teaching coordinate translation and its use in graphing curves]. Premisa [Premise], 18(71), 3-16.

Morales, A., \& Damián, A. (in press). Estrategia didáctica fundamentada en el uso de GeoGebra para mejorar la comprensión del concepto de semejanza de triángulos [Didactic strategy based on the use of GeoGebra to improve the understanding of the concept of similarity of triangles]. Innovación Educativa [Educational Innovation].

Morales, A., Marmolejo, J. E., \& Locia, E. (2014). El software GeogGebra: Un recurso heurístico en la resolución de problemas geométricos [GeogGebra software: A heuristic resource for solving geometric problems]. Premisa [Premise], 16(63), 20-28. 
Mosquera, M. C., \& Uzuriaga, V. L. (2018). Aprendizaje basado en problemas en didáctica de la matemática, caso: Solución de ecuaciones cuadráticas por el método de aplicación de áreas, mediado por cabri géometre II plus [Problem-based learning in mathematics education, case: Solution of quadratic equations by the area application method, mediated by cabri géometre II plus]. Acta Latinoamericana de Matemática Educativa [Latin American Act of Educational Mathematics], 31(2).

Natsai, L. H., Tendere, J., \& Chagwiza, C. J. (2020). Exploring the conceptual understanding of the quadratic function concept in teachers' colleges Zimbawe. EURASIA Journal of Mathematics, Science and Technology Education, 16(2), em1817. https://doi.org/10.29333/ejmste/112617

Ortiz, E., Vergel, M., \& Villamizar, F. Y. (2020). Experiencia didáctica para la introducción de la función cuadrática en el nivel secundaria a partir de la modelación de un fenómeno físico con las tecnologías digitales [Didactic experience for the introduction of the quadratic function at the secondary level from the modeling of a physical phenomenon with digital technologies]. El Cálculo y su Enseñanza, Enseñanza de las Ciencias y la Matemática [Calculus and its Teaching, Science and Mathematics Teaching], 15, 21-33.

Simon, M. A., \& Tzur, R. (2004). Explicating the role of mathematical task in conceptual learning: An elaboration of the hypothetical learning trajectory. Mathematical Thinking and Learning, 6(2), 91-104. https://doi.org/10.1207/s15327833mtl0602_2

Torres, P. (2013). La instrucción heurística en la formación de profesores de matemáticas [Heuristic instruction in the training of mathematics teachers]. In C. Dolores, M. García, J. A. Hernández, \& L. Sosa (Eds.), Matemática educativa: La formación de profesores [Educational mathematics: Teacher training] (pp. 205-221). Díaz de Santos.

Vega, A. (2016). Enseñanza del álgebra a través de la formalización progresiva [Teaching algebra through progressive formalization] [Undergraduate thesis].

Wilkie, K. J. (2022). Generalization of quadratic figural patterns: Schifts in student noticing. Journal of Mathematical Behavior, 65, 1-19. https://doi.org/10.1016/j.jmathb.2021.100917

Zakaria, E., Ibrahim, \& Maat, S. M. (2010). Analysis of students' error in learning of quadratic equations. International Education Studies, 3(3), 105-110. https://doi.org/10.5539/ies.v3n3p105 